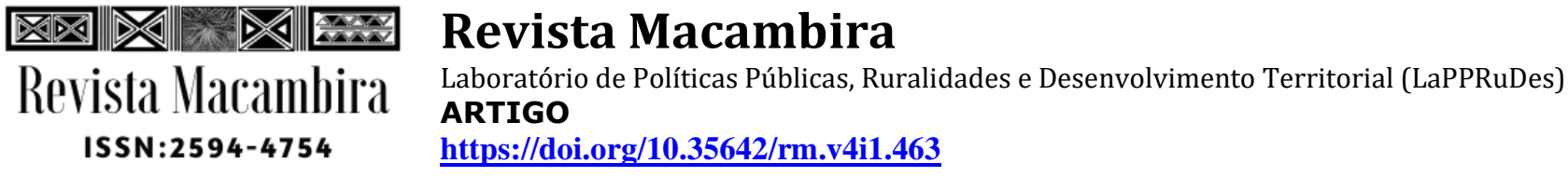

\title{
Mel de abelhas na alimentação de estudantes e servidores do IF Baiano campus Governador Mangabeira
}

\author{
Marília Dantas e Silva ${ }^{1 *}$, Ana Paula Oliveira Lima ${ }^{2}$, Cristiane Oliveira Costa ${ }^{3}$
}

\author{
${ }^{1}$ Docente do Instituto Federal de \\ Educação, Ciência e Tecnologia \\ Baiano, campus Governador \\ Mangabeira. Doutora em Ecologia \\ https://orcid.org/0000-0002-4896- \\ $\underline{6627}$ \\ ${ }^{2}$ Estudante do Curso Técnico em \\ Cozinha, no Instituto Federal de \\ Educação, Ciência e Tecnologia \\ Baiano, campus Governador \\ Mangabeira \\ https://orcid.org/0000-0002-5873- \\ $\underline{677 \mathrm{X}}$ \\ ${ }^{3}$ Nutricionista do Instituto Federal \\ de Educação, Ciência e Tecnologia \\ Baiano, Campus Governador \\ Mangabeira. \\ https://orcid.org/0000-0002-7543- \\ $\underline{8504}$
}

*Autor correspondente: marilia.silva@ifbaiano.edu.br

\begin{abstract}
Resumo:
Dos produtos fornecidos pelas abelhas, o mel é o mais conhecido e difundido. Foi um dos primeiros alimentos do homem, e praticamente todas as civilizações antigas o utilizaram como alimento e recurso medicinal. O presente trabalho teve como objetivo avaliar a utilização do mel de abelhas, por estudantes e servidores do Campus do IF Baiano de Governador Mangabeira e sensibilizar os mesmos sobre a importância do uso do mel. A coleta de dados ocorreu entre novembro de 2018 e março de 2019, através da aplicação de entrevistas estruturadas com 100 pessoas. Foi possível diagnosticar que 68\% dos estudantes e $62 \%$ dos servidores informaram ter o hábito do consumo do mel, sendo que utilizam com maior frequência quando estão doentes. No Brasil o consumo per capita anual de mel é de apenas $300 \mathrm{~g}$. Quando foi questionado sobre o que motivaria esse baixo consumo, os estudantes (43\%) indicaram que a falta de costume do uso do mel seria o motivo para essa realidade. Já 50\% dos servidores informaram que a falta de conhecimento sobre a importância do mel seria a principal razão. Em relação às atividades de sensibilização no Campus foram realizadas 11 palestras, uma oficina para a preparação de receitas à base de mel e a produção de uma cartilha informativa sobre mel. Todas essas ações foram muito positivas e acredita-se que contribuíram para um aumento no consumo do mel, que é um alimento altamente nutritivo, e que pode substituir os adoçantes industrializados com a mesma eficiência de sabor e de forma muito mais saudável.
\end{abstract}

Palavras-chave: Nutrição, Apis melífera, Alimentação saudável.
Instituto Federal de Educação, Ciência e Tecnologia Baiano, Campus Serrinha. Estrada Vicinal de Aparecida, s/n, Bairro Aparecida, Serrinha (Ba), CEP: 48700000, sala 01, prédio acadêmico. 


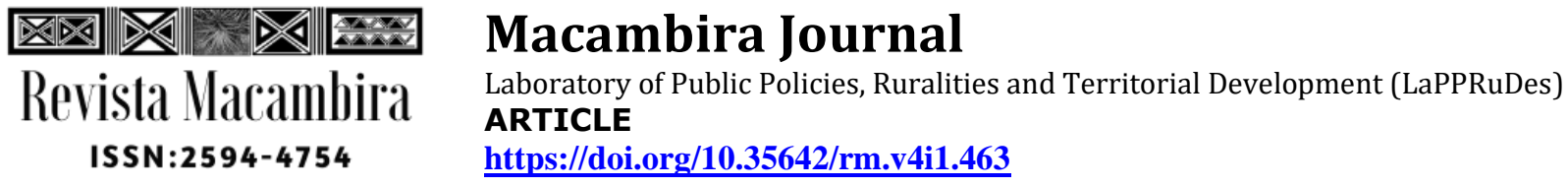

\title{
Honey in the food of students and servants of the IF Baiano campus Governador Mangabeira
}

\author{
Marília Dantas e Silva1*, Ana Paula Oliveira Lima², Cristiane Oliveira Costa ${ }^{3}$
}

\begin{abstract}
${ }^{1}$ Professor at the Federal Institute of Education, Science and Technology Baiano, campus Governador Mangabeira. PhD in Ecology https://orcid.org/0000-0002-4896$\underline{6627}$
\end{abstract}

${ }^{2}$ Student of the Technical Course in Cooking, at the Federal Institute of Education, Science and Technology Baiano, campus Governador Mangabeira https://orcid.org/0000-0002-5873$\underline{677 X}$

\footnotetext{
${ }^{3}$ Nutritionist at the Federal Institute of Education, Science and Technology Baiano, campus Governador Mangabeira. https://orcid.org/0000-0002-7543$\underline{8504}$
}

*Corresponding author: marilia.silva@ifbaiano.edu.br

\begin{abstract}
:
Among products supplied by bees, honey is the most well-known and widespread. Honey was one of the first foods of man, and practically all ancient civilizations used it as food and medicinal resource. Thid work evaluates ingestion of honey by students and servants of the IF Bahia Campus of Governador Mangabeira and sensitizes them on the importance of honey use. Data collection was between November 2018 and March 2019, through structured interviews with 100 people. We diagnosed $68 \%$ of students and $62 \%$ of servers having reported the habit of consuming honey, and they use it more frequently when they are sick. In Brazil the annual per capita consumption of honey is only $300 \mathrm{~g}$. When asked what motivated this low consumption, students (43\%) indicated that the lack of habit would be the reason for this reality. On the other hand, $50 \%$ of servants reported that the lack of knowledge about the importance of honey would be the main reason. Regarding awareness activities on the Campus, 11 lectures were held, a workshop for the preparation of recipes based on honey and the production of an information booklet on honey. All of these actions were very positive and are believed to have contributed to an increase in the honey consumption, which is a highly nutritious food, and which can replace industrialized sweeteners with the same flavor efficiency and, in a much healthier way.
\end{abstract}

Keywords: Nutrition, Apis melífera, Healthy eating.

Federal Institute of Education, Science and Technology Baiano, Campus Serrinha. Estrada Vicinal de Aparecida, s/n, Bairro Aparecida, Serrinha, Bahia, Brasil, CEP: 48700-000, sala 01, prédio acadêmico. 


\section{Introdução}

O mel é considerado um fluido viscoso, aromático e doce elaborado por abelhas a partir do néctar e/ou exsudatos sacarínicos de plantas, principalmente de origens florais, os quais, depois de levados para a colmeia pelas abelhas, são amadurecidos por elas e estocados no favo para sua alimentação (BRASIL, 2018). Ele é proveniente das abelhas e algumas vespas, porém devido a sua domesticação antiga, e por ser originária dos principais países consumidores, a abelha Apis mellifera Linnaeus 1758 é considerada como principal produtora do mel, apesar da grande diversidade de espécies de abelhas existentes e que produzem mel de boa qualidade, como as abelhas sem ferrão (CARVALHO et al. 2005). O mel é considerado o produto apícola mais fácil de ser explorado, sendo também o mais conhecido e com maiores possibilidades de comercialização. Além de ser um alimento, é também utilizado em indústrias farmacêuticas e cosméticas, pelas suas conhecidas ações terapêuticas (CAMPOS; MODESTA, 2000).

O mel é um alimento muito rico e de elevado valor energético, consumido mundialmente e de extrema importância para a saúde do organismo humano, por apresentar diversas propriedades: antimicrobiana, curativa, calmante, pré-biótica, regenerativa de tecidos, estimulante, dentre outras (BIZZARIA; FILGUEIRAS, 2003). A presença de algumas substâncias, como os compostos fenólicos, aminoácidos, vitaminas, sais minerais, ácidos orgânicos e enzimas, embora não sejam minoritários, atribuem efeitos terapêuticos ao mel, despertando o interesse não só dos consumidores como também de pesquisadores. Estudos mostram que a composição do mel o torna um produto com atividade antimicrobiana, promotor da cicatrização de ferimentos, antioxidante, além de ser uma boa fonte de energia, atuando não apenas como adoçante, mas também promovendo saúde ao organismo humano. Todos estes fatores têm proporcionado a incorporação de mel de abelha em vários produtos alimentícios, visto a sua importância terapêutica e fonte natural adoçante (SILVA et al., 2006).

Nos últimos anos, o consumo de mel tem aumentado significativamente no mundo todo, em virtude da busca pelo consumo de produtos naturais (BERTOLDI, 2008). Este fator tem impulsionado uma melhoria na qualidade do mel produzido, visando a segurança alimentar através de um produto natural, livre de contaminantes e microrganismos e, dessa forma, a aceitação do mesmo nos mercados internacionais. Contudo, de uma forma geral, ainda é necessário que o mel esteja presente em uma maior frequência na alimentação diária das pessoas, e para isso é necessário mais informação e sensibilização sobre as propriedades terapêuticas, medicinais e energéticas do mel. O presente trabalho teve como objetivo avaliar a utilização do mel de abelhas por estudantes e servidores do Campus do IF Baiano de Governador 
Mangabeira e sensibilizar a comunidade sobre a importância do uso do mel, não só como medicamento, mas principalmente como fonte energética para uma dieta saudável e equilibrada.

\section{Desenvolvimento}

O Instituto Federal de Educação, Ciência e Tecnologia Baiano, Campus Governador Mangabeira foi criado em primeiro de agosto de 2011 e está localizado na Região do Recôncavo Sul da Bahia, a 119 Km da capital do Estado. O município possui área territorial de $94,359 \mathrm{~km}^{2}$ e sua população é de 19.818 habitantes (IBGE, 2019) e ocupa a posição de 47. lugar no ranking do Índice de Desenvolvimento Humano (IDH) do Estado. O Campus apresenta atualmente os seguintes cursos: Técnico em Informática Integrado ao Ensino Médio, Técnico em Agroindústria Integrado ao Ensino Médio, Técnico em Agropecuária Integrado ao Ensino Médio, Técnico em Cozinha Integrado ao Ensino Médio (PROEJA), Técnico Subsequente em Manutenção e Suporte em Informática, Técnico Subsequente em Agropecuária e Técnico Subsequente em Alimentos.

Em decorrência da importância da inclusão do mel na alimentação diária da comunidade do Campus do IF Baiano de G. Mangabeira decidiu-se realizar, entre novembro de 2018 e fevereiro de 2019, a aplicação de questionários (entrevistas estruturadas) com 100 pessoas, entre servidores e estudantes do Campus. O principal objetivo dessa metodologia foi diagnosticar como ocorre a utilização do mel entre a comunidade através de algumas perguntas como: qual a frequência da sua utilização; se é utilizado apenas como medicamento; se faz parte da alimentação diária; quais os tipos de alimentos consumidos que levam mel na sua composição; se considera o mel um alimento caro e o porquê do baixo consumo de mel no Brasil.

Em relação às entrevistas realizadas, foi possível indicar que $68 \%$ dos estudantes e $62 \%$ dos servidores informaram ter o hábito do consumo do mel, sendo que utilizam com maior frequência quando estão doentes (40\% dos estudantes e 31,2\% dos servidores). De acordo com Perosa et al. (2004) a falta de informação provoca desconhecimento das propriedades nutritivas do mel que passa a ser consumido, exclusivamente, como remédio e não como alimento. Zamberlan \& Santos (2010) verificaram em uma pesquisa sobre o hábito do consumo de mel entre representantes de associações de apicultores, consumidores e varejistas em Caxias do Sul-RS, que 69,7\% dos entrevistados consomem mel com maior frequência, (uma vez por semana ou diariamente), o que demonstra um resultado semelhante ao encontrado no presente trabalho. Ribeiro et al., 2010 identificaram em estudo realizado em Bragança, Portugal, que 84,2\% dos entrevistados consomem mel com regularidade, sobretudo nas épocas frias, sendo que 17,4\% consomem todos os dias, 34\% pelo menos uma vez por semana, 22\% pelo menos uma vez por mês. Vilckas et al. (2001) conduziram um estudo em Ribeirão Preto-SP, no qual verificaram que 25,2\% dos inquiridos nunca 
consumiam mel, e os que afirmavam consumir mel faziam-no poucas vezes (43,1\%). No presente estudo a maioria adquire o mel direto do produtor (estudantes 56,3\% e servidores 38,8\%) e isso pode ser explicado pelo fato que na região existe muitos apicultores, o que facilita a compra direta com os produtores de mel.

No Brasil o consumo per capita anual de mel é de apenas 300g (ZAMBERLAN; SANTOS, 2010). Quando foi questionado sobre o que motivaria esse baixo consumo, os estudantes (43\%) indicaram que a falta de costume do uso do mel seria o motivo para essa realidade. Já 50\% dos servidores informaram que a falta de conhecimento sobre a importância do mel seria a principal razão. Segundo Zamberlan \& Santos (2010) em entrevistas realizadas sobre consumo de mel, um dos maiores problemas identificados foi a falta de conhecimento acerca das propriedades do mel, dos seus benefícios e usos. Eles indicam neste trabalho, a necessidade de um esforço de promoção do mel, e perceberam que a maioria dos entrevistados, que conhece os benefícios do mel, o consome com maior frequência. Altamente nutritivo, o mel pode substituir os adoçantes industrializados com a mesma eficiência de sabor e, de forma muito mais saudável (SILVA et al., 2006). Por esse e outros fatores existe a necessidade da sensibilização das pessoas sobre a importância de incluir o mel na alimentação diária, através de cursos, palestras, distribuição de cartilhas, sites informativos etc.

Aproximadamente $41 \%$ dos estudantes informaram não achar o mel um produto caro, enquanto que os 37\% dos servidores apresentaram a mesma opinião. Zamberlan \& Santos (2010) observaram que a opinião das pessoas ficou equilibrada entre uma avaliação de preço do mel em razoável (41,3\%) e caro (42\%). De uma forma geral, o mel é visto como um produto caro, mas como indicado anteriormente, tanto os estudantes quanto os servidores em sua grande maioria adquirem o mel direto com criadores de abelhas, o que acaba proporcionando o acesso a preços mais baixos.

Posteriormente a realização das entrevistas e com a finalidade de sensibilizar a comunidade do Campus do IF Baiano de G. Mangabeira, sobre as propriedades do mel, sua importância e necessidade da inclusão do mesmo na alimentação diária, foi realizado em 17 de dezembro de 2018 uma palestra para estudantes e servidores, durante um evento para a apresentação de Projetos dos estudantes. Além disso, foram distribuídos por toda a área do Campus dois tipos de cartazes informativos sobre o tema (Figura 1).

Entre março e maio de 2019 mais palestras de sensibilização (Figura 2) foram realizadas em sala de aula com estudantes dos cursos Técnicos em Agroindústria, Cozinha, Agropecuária e Alimentos, totalizando 10 turmas. No final das apresentações foram mostrados, para os estudantes e professores presentes, diferentes tipos de méis, de distintas cores (claro, escuro e intermediário) e texturas. Além disso, foi mostrado o mel cristalizado e perguntado o que os presentes faziam quando o mel adquire a forma "açucarada". A 
grande maioria falou que consome o mel com essa textura e alguns informaram que colocam em banho maria, para que o mel volte a sua textura original. Zamberlan \& Santos (2010) verificaram entre os entrevistados sobre o consumo do mel, que 46\% manifestaram alguma desconfiança com a qualidade do produto quando o mesmo se encontrava cristalizado. A cristalização do mel é um processo natural que ocorre devido à separação da glicose da frutose, formando cristais. O tipo da origem floral, o pólen e o néctar das flores utilizado pelas abelhas para produzir o mel são fatores que interferem na rapidez da cristalização do mel. Dependendo da temperatura e da florada, o mel leva mais ou menos tempo para cristalizar (SILVA et al., 2006).

Figura 1 - Cartazes distribuídos no Campus do IF Baiano de Governador Mangabeira. A) Os 7 benefícios do mel; B) Propriedades do mel. Governador Mangabeira, 2018.

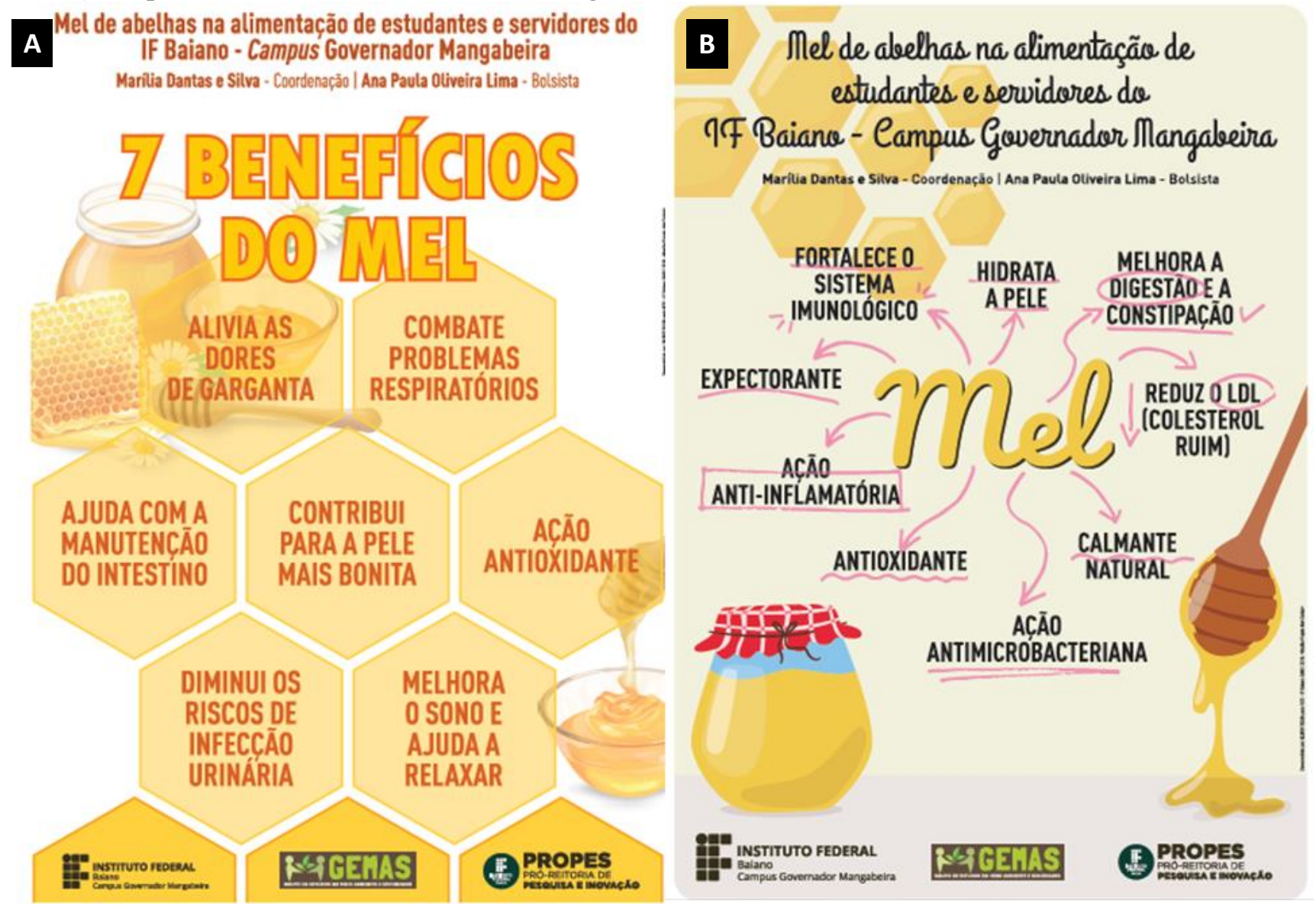

Fonte: Elísio Silva, 2018.

Foi realizada ainda uma degustação de mel entre os presentes, para que pudessem comparar o sabor, aroma e textura de méis das espécies Apis mellifera, Melipona scutellaris Latreille, 1811 e Tetragonisca angustula Latreille, 1811. Essa ação ocorreu como uma forma de apresentar mel de diferentes espécies de abelhas, além 
de discutir com os estudantes sobre o hábito do consumo do mel e finalizar a palestra de uma forma dinâmica e divertida. De um modo geral, os estudantes de todas as turmas, tiveram preferência pelo mel de Apis mellifera, já que é o mais conhecido pelo paladar dos mesmos. As outras duas espécies são meliponíneos, abelhas indígenas sem ferrão, cujos méis não são fáceis de encontrar no mercado e apresentam preços muito mais altos que o mel da abelha africanizada. Embora produzam mel em menor quantidade, os meliponíneos são importantes por fornecer um produto que se diferencia do mel de $A$. mellifera, principalmente na doçura inigualável, sabor diferenciado mais aromático e que proporciona alcançar altos preços no mercado (NOGUEIRA-NETO, 1997; CARVALHO et al., 2005).

Figura 2 - Palestras de sensibilização realizadas no Campus do IF Baiano de Governador Mangabeira. A) Turma do Módulo 2 de Alimentos 2019.1; B) Turma do $2^{\circ}$ ano de Agroindústria, 2019; C) Turma do $1^{\circ} \mathrm{A}$ de Agroindústria, 2019; D) Turma do Módulo 1 de Alimentos 2019.1. Governador Mangabeira, 2019.

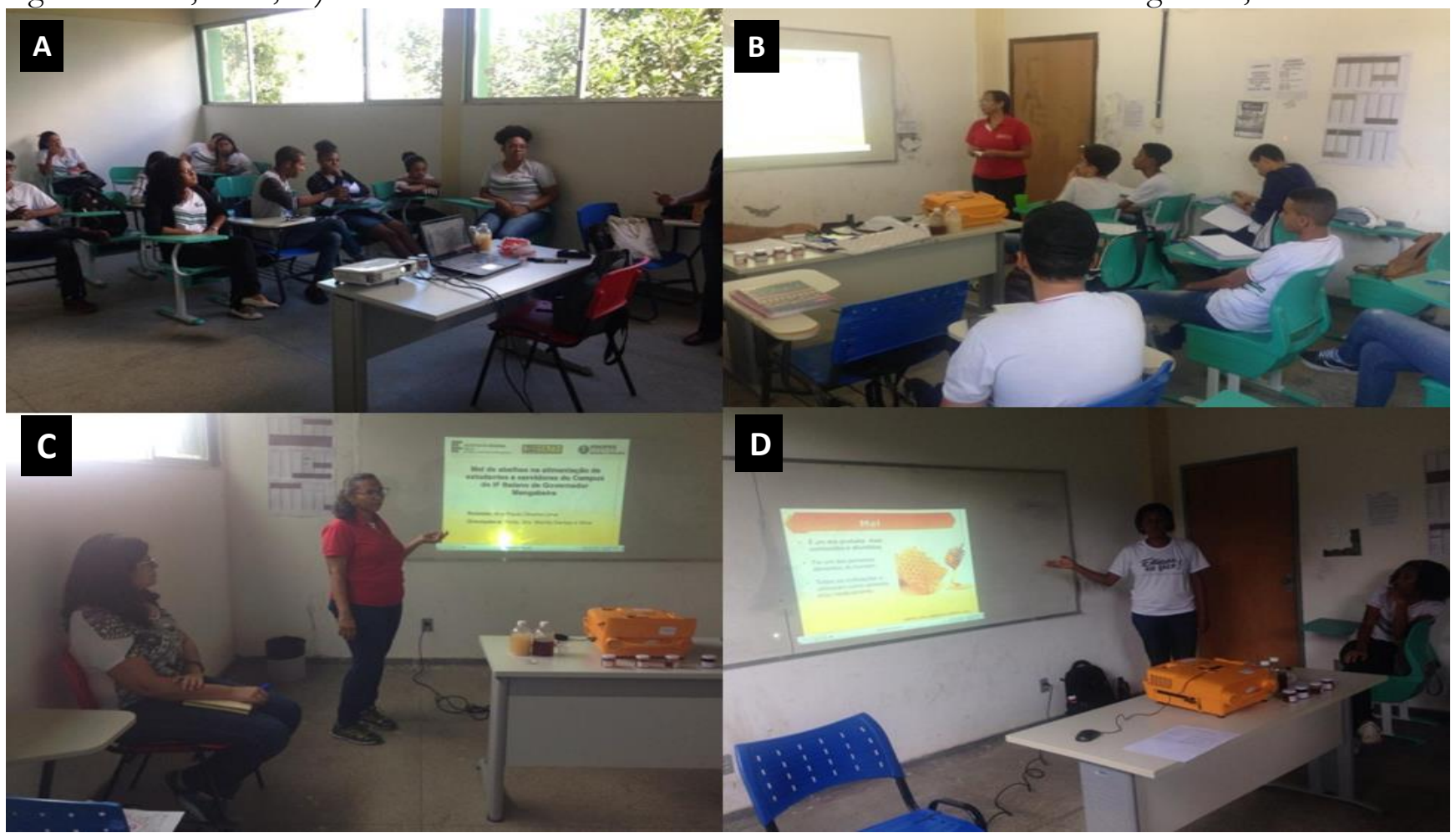

Fonte: Ana Paula Lima e Cristiane Santos (Acervo pessoal), 2019.

Para complementar as ações de sensibilização, sobre a importância da inclusão do mel na alimentação diária, no dia 12 junho de 2019 foi realizada uma oficina sobre receitas a base de mel (Figura 3), com as turmas do segundo e terceiro anos do curso Técnico de Cozinha do Campus, para preparação de receitas que utilizam o mel como principal ingrediente. O objetivo dessa proposta foi mostrar para os estudantes novas formas de utilização do mel, além do uso in natura. No total 15 estudantes participaram da oficina, que teve duração de 4 horas. Eles receberam uma apostila com algumas informações sobre o mel e as receitas que 
seriam realizadas. Foram selecionadas no total treze receitas, entretanto, em decorrência do tempo, apenas cinco foram escolhidas para serem preparadas no dia, que foram: pão de mel, sorvete de mel, barra de cereal com mel, pipoca com mel e molho de mostarda e mel. Essas receitas foram testadas previamente e realizados testes de degustação, com alguns servidores e estudantes do Campus, para a confirmação de quais teriam melhor aceitação.

Figura 3 - Oficina para preparação de receitas à base de mel. A) Organização dos materiais necessários para a preparação das receitas; B) Preparação da barra de cereal; C) Degustação das receitas; D) Preparação do pão de mel. Governador Mangabeira, 2019.

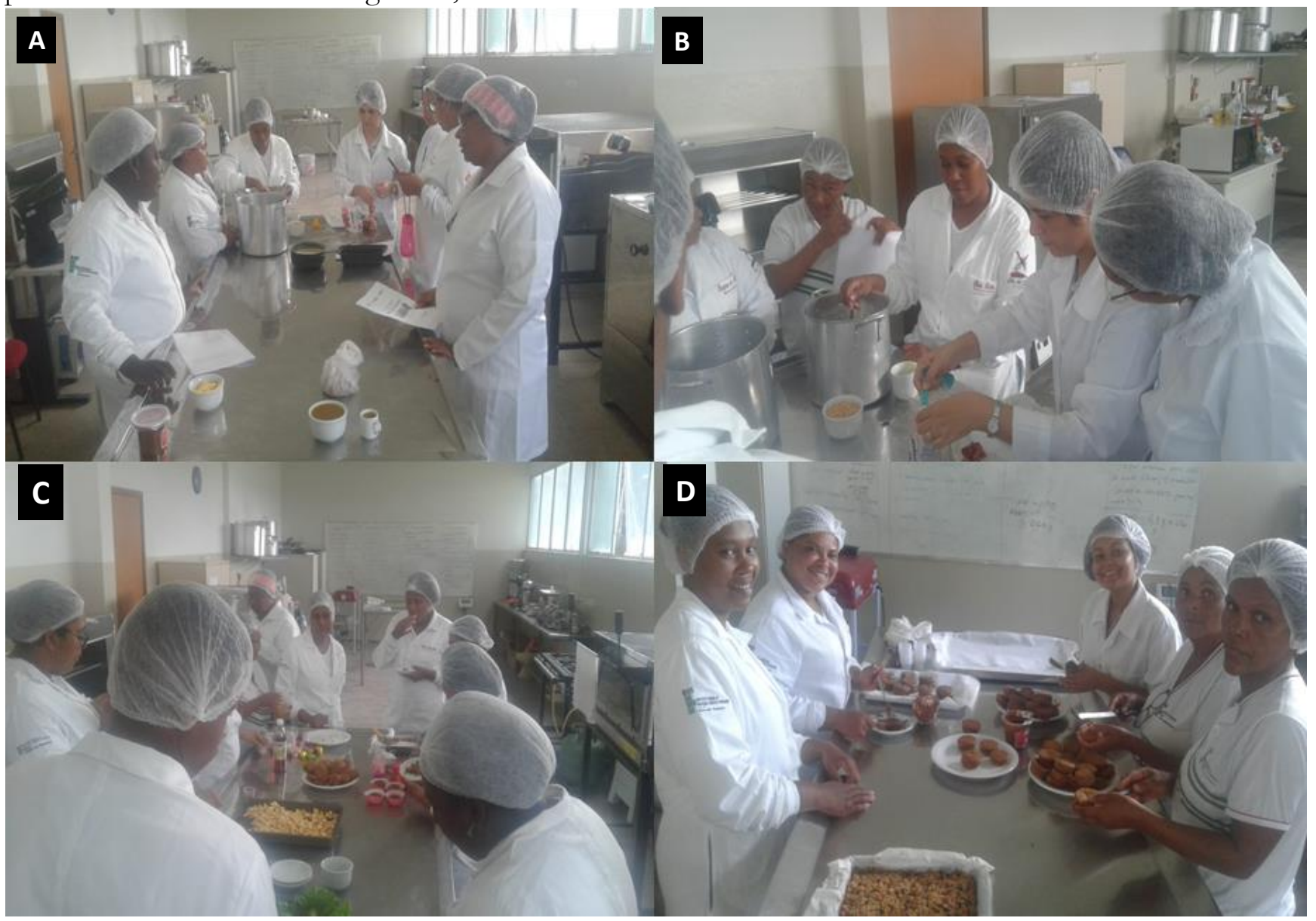

Fonte: Ana Paula Lima (Acervo pessoal), 2019.

Os participantes da oficina não tinham o hábito de utilizar o mel em receitas do seu dia a dia e ficaram surpresos com as possibilidades de utilização em receitas doces e salgadas. Os mesmos falaram que pretendem reproduzir as mesmas nas suas casas inclusive para comercialização, como é o caso do pão de mel e da barra de cereal.

E para finalizar as ações de sensibilização e informar um número maior de pessoas quanto a importância do mel, foi desenvolvida uma cartilha intitulada "O Mel de Abelhas" (com dados sobre o mel, 
sua utilização, importância, propriedades e receitas a base de mel - Figura 4), que foi lançada na Feira de Ciência e Tecnologia do Campus do IF Baiano de Governador Mangabeira nos dias 12 e 13 de novembro de 2019. A mesma cartilha foi distribuída no Campus, enviada para as coordenações de Pesquisa e Extensão de todos os Campi do IF Baiano e também está disponível digitalmente no seguinte site https://www.smaifbaianogm.eco.br/p/blog-page_20.html.

\section{Conclusão}

De uma forma geral a comunidade do Campus do IF Baiano de G. Mangabeira demonstrou conhecer a importância do mel e a grande maioria tem o hábito do seu consumo no seu dia a dia. Contudo a maior parte dos entrevistados, se limita a utilizar o mel apenas quando estão doentes. Através das atividades realizadas para a sensibilização da comunidade (palestras, oficina e cartilha) foi possível sensibilizar um grande número de pessoas sobre as propriedades do mel, sua importância e possibilidade da utilização in natura e também na forma de diversas receitas fáceis de serem realizadas. Acredita-se que o presente trabalho poderá contribuir para um aumento do uso do mel entre os envolvidos, visto que muitos se surpreenderam com as informações passadas durante o desenvolvimento das atividades.

\section{Agradecimentos}

A Pró-Reitoria de Pesquisa e Inovação - IF Baiano e ao CNPq pelo apoio financeiro e concessão das bolsas de Iniciação Científica PIBIC Júnior. Aos servidores e estudantes do Campus do IF Baiano de Governador Mangabeira pela colaboração durante a pesquisa. 
Figura 4 - Capa e contra capa da cartilha sobre mel, para sensibilização da comunidade do Campus. A) Capa da cartilha "O mel de abelhas"; B) Contra capa da cartilha "O mel de abelhas"; C) Receitas à base de Mel; D) Exemplos de receitas presentes na cartilha, pudim de mel e biscoito de mel. Governador Mangabeira, 2019.
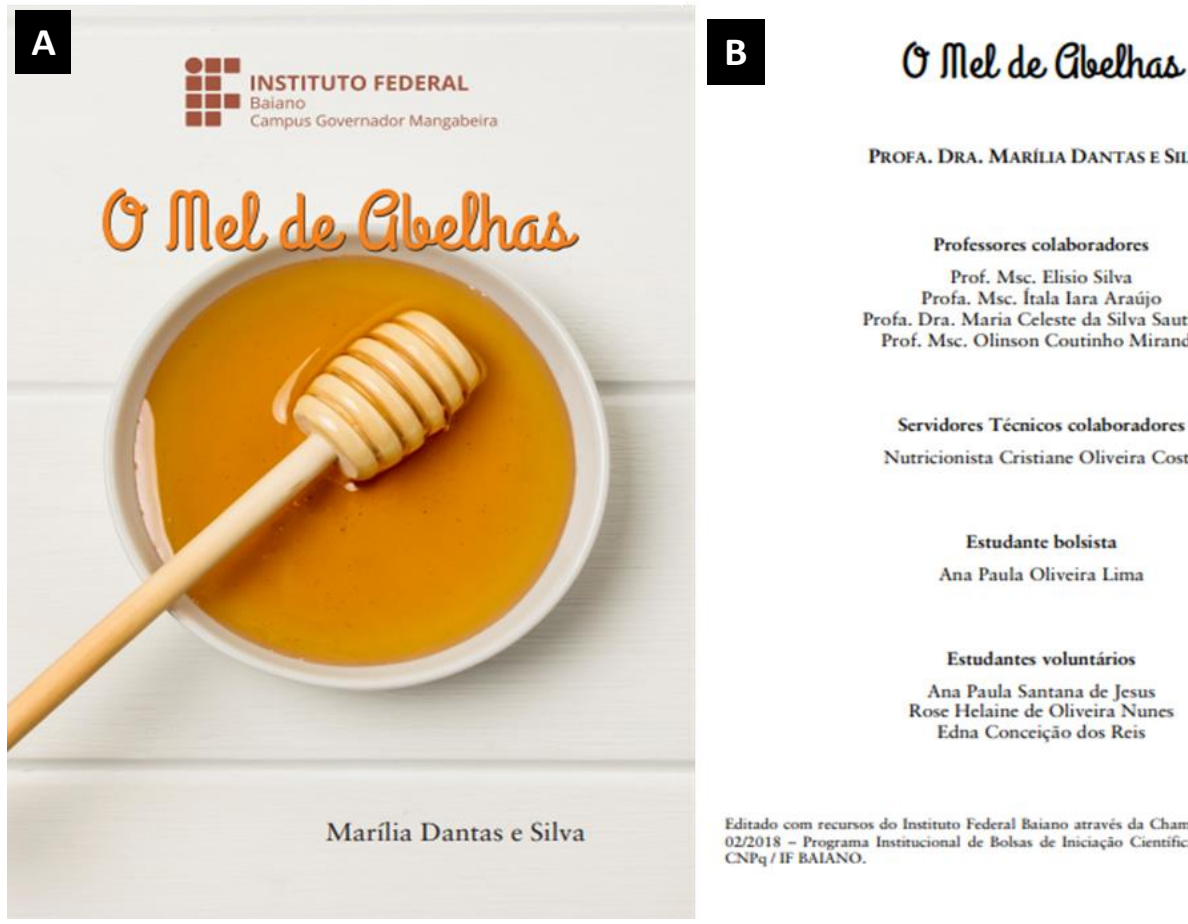

\section{C}

D Profa. Dra. Marilua Dantas e Silva

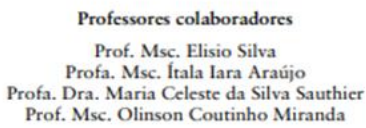

Editado com recursos do Instituto Federal Baiano através da Chamada interna PROPES N02/2018 - Programa Institucional de Bolsas de Iniciagao Cientifica PIBIC Ensino Médio
CNPq /E RAIANO. ty. Pudim demel

Ingredientes:

2 copos de mel

$1 / 2$ quilo de farinha de rosca

6 ovos

Receitas à base de mel

1 colher de chá de canela em pó

Modo de preparo

Misturar tudo até obter uma massa bastante mole. Levar ao forno quente durante meia hora, deixar esfriar e colocar na geladeira.

\section{Biscrita de mel,}

Ingredientes:

3 xícara de chá de mel

$300 \mathrm{~g}$ de açúcar mascavo

$250 \mathrm{~g}$ de farinha de trigo integral

$150 \mathrm{~g}$ de amendoas sem casca

1 colher de café de noz-moscada

2 cravos da india

2 colheres de sopa de raspas de limåo

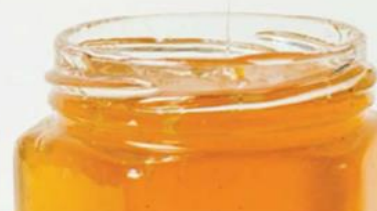

$1 / 2$ xicara de chá de conhaque

Modo de preparo:

Aquecer o mel até ferver. Bater no processador as amêndoas com o açúcar. Juntar a farinha, a noz-moscada, o cravo moído, as raspas do limão e o conhaque. Misturar tudo e acrescentar o mel bem quente. Amassar de modo que a massa fique dura. Abrir a massa e levar ao forno para assar em forma polvilhada com farinha de trigo. Depois de pronta, cortar em tiras.

Fonte: Marília Silva (Acervo pessoal). 2019. 


\section{Referências}

BERTOLDI, C. R. C. Meliponicultura uma alternativa sustentável. Embrapa. 2008. Disponível em https://www.embrapa.br/embrapa/imprensa/noticias/2008/agosto/2a-semana/meliponicultura-umaalternativa-sustentavel. Acesso em: 03 maio. 2018.

BIZZARIA, D. K.; FILGUEIRAS, C. T. 2003. Análise microbiológica de mel de abelha, consumido no município de Campo Grande-MS. Hig. Alim., v. 17, p. 104-105.

BRASIL. Ministério da Agricultura, Pecuária e Abastecimento, Instrução Normativa 11, de 20 de outubro de 2000, Regulamento técnico de identidade e qualidade do mel. Disponível em: http://www.agricultura. gov.br/das/dipoa/anexo_intrnorm11. htm. Acesso em: 03 maio. 2018.

CAMPOS, G.; MODESTA, R. C. D. 2000. Diferenças sensoriais entre mel floral e mel de melato. Rev. Inst. Adolfo Lutz, v. 59, n. 1-2, p. 7-14.

CARVALHO, C. A. L.; SOUZA B.; SODRÉ, G. S.; MARCHINI, L.C.; ALVES, R. M. O. 2005. Mel de abelhas sem ferrão: contribuição para a caracterização físico-química - Cruz das Almas: Universidade Federal da Bahia/SEAGRI-BA. Série Meliponicultura, 32 p.

IBGE. Panorama Governador Mangabeira, Bahia, Brasil. Censo 2010. Disponível em: https://cidades.ibge.gov.br/brasil/ba/governador-mangabeira/panorama. Acesso em: 20 out. 2019.

NOGUEIRA-NETO, P. 1997. Vida e criação de abelhas indígenas em ferrão. São Paulo: Editora Nogueirapis. 446p.

PEROSA, J., ARAUCO, E., SANTOS, M. ALBARRACIN, V. 2004. Parâmetros de competitividade do mel Brasileiro. Revista Informações Económicas, Vol. 34, n³, pp. 41-48.

RIBEIRO, B. M.; FERNANDES, A.; MATOS, A. CABO, P. 2010. Produtos Locais: o consumo de mel no distrito de Bragança, Portugal. Congresso de Estudos Rurais Mundos Rurais em Portugal - Múltiplos Olhares, Múltiplos Futuros Universidade de Aveiro, 4 a 6 de Fevereiro de 2010.

SILVA, R. A.; MAIA, G. A.; SOUSA, P.H. M.; COSTA, J. M. C. 2006. Composição e propriedades terapêuticas do mel de abelha. Alim. Nutr., Araraquara v.17, n.1, p.113-120, jan./mar.

VILCKAS, M., GRAMACHO, K., GONÇALVES, L., MARTELLI, D. (2001). Perfil do Consumidor de Mel e o Mercado de Mel. Mensagem Doce, Vol. 64, pp. 5-17.

ZAMBERLAN, L.; SANTOS, D. M. Santos. O comportamento do consumidor de mel: um estudo exploratório. Revista de Administração e Ciências Contabeis do Ideau. 2010. 21p. 


\begin{abstract}
Informações do Artigo
Recebido em: 21/05/2020

Aceito em: 16/06/2020

Publicado em: 25/06/2020

Conflitos de Interesse: Os autores declaram não haver quaisquer conflitos de interesse referente a este artigo.
\end{abstract}

\section{Como citar este artigo}

Silva, M., Lima, A. P., \& Costa, C. (2020). Mel de abelhas na alimentação de estudantes e servidores do IF Baiano campus Governador Mangabeira. Revista Macambira, 4(1), e041001. https://doi.org/10.35642/rm.v4i1.463.

Licença:

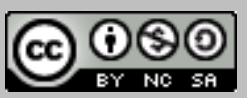

Este trabalho está licenciado sob uma Licença Internacional Creative Commons AttributionNonCommercial-ShareAlike 4.0 International.
Article Information

Received on: 21/05/2020

Accepted in: 16/06/2020

Published on: 25/06/2020

Conflict of Interest: No reported.

How to cite this article

Silva, M., Lima, A. P., \& Costa, C. (2020). Honey in the food of students and servants of the IF Baiano campus Governador Mangabeira. Revista Macambira, 4(1), e041001. https://doi.org/10.35642/rm.v4i1.463

License:

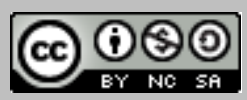

This work is licensed under a Creative Commons Attribution-NonCommercialShareAlike 4.0 International License. 